TABLE I

\begin{tabular}{|c|c|c|c|c|}
\hline$I C D-9$ & \multicolumn{2}{|c|}{ Diagnosis } & $\begin{array}{c}\text { Priory Emergency Service } \\
\text { (Private) }\end{array}$ & $\begin{array}{c}\text { Charing Cross } \\
\text { Emergency Service } \\
\text { (NHS) }\end{array}$ \\
\hline \multirow{3}{*}{$\begin{array}{l}296.1,3,300.4 \\
296.0 \\
295 \\
300,300.2 \\
303,304 \\
301 \\
293 \\
307.1\end{array}$} & Depression & $\begin{array}{l}\text { Endogenous } \\
\text { Reactive }\end{array}$ & $23 \%$ & $23 \%$ \\
\hline & \multicolumn{2}{|c|}{$\begin{array}{l}\text { Mania } \\
\text { Schizophrenia } \\
\text { Anxiety-phobic states } \\
\text { Alcohol/drug dependency } \\
\text { Personality disorders } \\
\text { Acute confusional state } \\
\text { Anorexia nervosa }\end{array}$} & $\begin{array}{c}11.8 \% \\
15.7 \% \\
9.8 \% \\
25 \% \\
2 \% \\
6 \% \\
6 \%\end{array}$ & $\begin{array}{c}2 \% \\
14 \% \\
11 \% \\
30 \% \\
21 \% \\
0.5 \% \\
-\end{array}$ \\
\hline & \multicolumn{2}{|c|}{ Total $=$} & $100 \%$ & $100 \%$ \\
\hline
\end{tabular}

those at Charing Cross Hospital. The emergency service at The Priory provides a 24-hour assessment service, domiciliary visits, advice for general practitioners in dealing with psychiatric emergencies and urgent admissions. We saw $\mathbf{5 3}$ new cases in a threemonth period. The diagnostic categories compared with those of the Charing Cross patients during the same period are shown in Table I.

It may surprise some to see the similarities between the private and public sectors, especially in relation to the major psychoses, neurotic disorders and alcohol and drug dependency. The higher proportion of patients with personality disorders seen at Charing Cross is of particular interest.

I cannot, of course, speak for the whole of the private psychiatric sector, but The Priory Hospital at least is prepared and able to meet the needs of a representative sample of psychiatric patients.

I hope the two hospitals can now collaborate on a follow-up study of their patients.

SAEED IsLAM

The Priory Hospital

Roehampton SW15 5JJ

\section{A great mystery of psychotherapy practice}

DeAR SirS

For some time I have been concerned about an interesting phenomenon of psychotherapy practice and the other day a patient came to see me for a consultation and what unfolded captured the issue fairly well.

The patient, in this case a woman, comes to see me as consultant psychotherapist at an acute psychiatric unit. She starts by saying that she saw this psychiatrist (who referred her) and all he wanted to do was ask her lots of questions, and tell her what to do, and get her to take drugs - he was not interested at all in her feelings and did not seem to have time to listen to her. I commiserate, indicate that there is time now and ask her gently to tell me about it.

"Oh but doctor couldn't you ask me some questions? I need to know what to do about my husband. Perhaps there is something I could take that could make me feel better?"

A colleague of mine once put the problem another way by pointing out that when the patient sees the psychiatrist and says "I want psychotherapy" the psychiatrist says "No, you don't"; then when the patient sees the psychotherapist and he says "You want psychotherapy", the patient says "Oh no, I don't”.

I contend that this is a great unsolved mystery worthy of detailed research!

\section{Seymour Clinic \\ Kingshill Road}

Swindon SN1 4LY

\section{Continuity of care}

\section{DeAR SIRS}

We were interested to read the account by Shah \& Lynch (Psychiatric Bulletin, March 1990, 14, 153-154) describing their study of cases attending a registrar's follow-up clinic. We recognise that it is dangerous to draw firm conclusions from such a small sample but we are surprised that they did not comment further on the fact that $87 \%$ of the patients had a diagnosis of schizophrenia or manic-depressive illness. Both of these groups represent a vulnerable population who need long-term support and therapy. As a general principle such individuals need maximum continuity of care and expert input and these cannot be found in a registrar clinic where the doctor usually changes at least every six months. We believe 
that these individuals deserve and need follow-up by trained members of the permanent staff. We recognise that this has implications in terms of the organisation of both service and training arrangements and requires further debate within the College.

We would suggest that audit of follow-up arrangements for these groups of patients must be a high priority for the College if we are to avoid the risk of having 'back ward' type care in the community.

I. A. DAVIDSON

R. G. POOLE

Central Liverpool Mental Health Team

Royal Liverpool Hospital

Liverpool L7 8XP

\section{Long-interval job-sharing}

DEAR SIRS

Job-sharing is now accepted practice in the NHS. It is attractive to married women with children, and to those approaching retirement. So far the sharing has been on a weekly basis, with the week's sessions divided between two people. I am exploring the possibility of sharing on the basis of longer intervals, such as two or three months. This might be attractive to women with children at school who want to work during the school terms but not during the holidays, and to those approaching retirement who want to develop interests which require longer periods than a few days. My own interest is off-shore sailing which requires a month or two to allow a satisfactory passage.

The main drawback to the idea is any possible adverse effect on patients or other staff. After discussions with local colleagues, managers and paramedical staff, it seems to me that it is worth trying, possibly with a built-in 'action research' project to evaluate it. I should be interested to hear from others who might find such an arrangement attractive.

As Benjamin Franklin is said to have said, there's no harm in retirement so long as it doesn't interfere with your work.

Department of Psychiatry

JoHN S. PRICE

Milton Keynes General Hospital

Standing Way

Milton Keynes MK6 5LD 